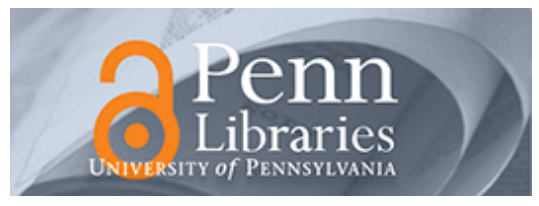

University of Pennsylvania ScholarlyCommons

9-1995

\title{
Minimizing Technological Oversights: A Marketing Research Perspective
}

Jehoshua Eliashberg

University of Pennsylvania

Gary L. Lilien

Vithala R. Rao

Follow this and additional works at: https://repository.upenn.edu/marketing_papers

Part of the Business Analytics Commons, Management Information Systems Commons, Management Sciences and Quantitative Methods Commons, Marketing Commons, and the Technology and Innovation Commons

\section{Recommended Citation}

Eliashberg, J., Lilien, G. L., \& Rao, V. R. (1995). Minimizing Technological Oversights: A Marketing Research Perspective. Retrieved from https://repository.upenn.edu/marketing_papers/254

This is an unpublished manuscript.

This paper is posted at ScholarlyCommons. https://repository.upenn.edu/marketing_papers/254

For more information, please contact repository@pobox.upenn.edu. 


\title{
Minimizing Technological Oversights: A Marketing Research Perspective
}

\author{
Abstract \\ Technological advances provide vast opportunities for new product development. Some technologies are \\ transformed into successful new products; others are not. In this paper we investigate the role that \\ marketing research methods as currently conceived can play in aligning marketplace needs with \\ technological potential. We discuss the types of opportunities that new technologies present to the \\ marketplace and why the existing set of market research methods are insufficient to assess the potential \\ for all of these new technologies. We then discuss some emerging, non-traditional marketing research \\ methods and assess their potential for addressing the technological oversights problem. We conclude \\ with implications for academics and for practitioners. \\ Disciplines \\ Business | Business Analytics | Management Information Systems | Management Sciences and \\ Quantitative Methods | Marketing | Technology and Innovation

\section{Comments} \\ This is an unpublished manuscript.
}




\section{Minimizing Technological Oversights: \\ A Marketing Research Perspective}

Jehoshua Eliashberg

Gary L. Lilien

Vithala R. Rao

ISBM REPORT 9-1995

Institute for the Study of Business Markets

The Pennsylvania State University

402 Business Administration Building

University Park, PA 16802-3004

(814) 863-2782 or (814) 863-0413 Fax 


\section{This publication is available in alternative media on request.}

The Pennsylvania State University is committed to the policy that all persons shall have equal access to programs, facilities, admission, and employment without regard to personal characteristics not related to ability, performance, or qualifications as determined by University policy or by state or federal authorities. The Pennsylvania State University does not discriminate against any person because of age, ancestry, color, disability or handicap, national origin, race, religious creed, sex, sexual orientation, or veteran status. Direct all inquiries regarding the nondiscrimination policy to the Affirmative Action Director, the Pennsylvania State University, 201 Willard Building, University Park, PA 16802-2801; tel. (814) 863-0471; TDD (814) 8653175.

U.Ed. BUS 95-079 


\title{
Minimizing Technological Oversights: A Marketing Research Perspective
}

\author{
Jehoshua Eliashberg \\ University of Pennsylvania \\ Gary L. Lilien \\ Penn State University \\ Vithala R. Rao \\ Cornell University
}

\begin{abstract}
Technological advances provide vast opportunities for new product development. Some technologies are transformed into successful new products; others are not. In this paper we investigate the role that marketing research methods as currently conceived can play in aligning marketplace needs with technological potential. We discuss the types of opportunities that new technologies present to the marketplace and why the existing set of market research methods are insufficient to assess the potential for all of these new technologies. We then discuss some emerging, non-traditional marketing research methods and assess their potential for addressing the technological oversights problem. We conclude with implications for academics and for practitioners.
\end{abstract}

\section{Prepared for Presentation at Technological Oversights and Foresights Conference Leonard N. Stern School of Business New York University}

April 10, 1994 


\section{Introduction}

....if the weight of invention or discovery is one, the weight to bring it to actual development should be ten and the weight to produce and market it should be one hundred.

\section{Masru Ibuka \\ President of Sony}

In spite of increasingly experienced management, the majority of new products fail to achieve their anticipated level of success in the marketplace. The causes for that lack of consistent market success have been the subject of much academic study (see Lilien and Yoon, 1989 for a review). That literature is consistent with the results of a recent survey by a consulting firm, EFO Ltd., that reports that among 154 senior marketing officers of US corporations:

$-79 \%$ believe the new product development process could be improved $-58 \%$ do not rate $R \& D$ as a successful source of new products $-46 \%$ do not rate R\&D's contribution to new product development as significant

As for the reasons for their perception of why this process is less than ideal, consistent with the findings of Booz-Allen and Hamilton (1982) they report:

-products don't offer a competitive point of difference (52\%) -product doesn't deliver as promised (43\%)

In addition, $61 \%$ of the respondents expect that $30 \%$ or more of their sales will come from new products within the next 3-5 years. Finally, EFO reports that they have conducted this research periodically and the companies are getting more concerned: 
firms see new products as a source of hope but they are showing ever more frustration over their internal processes for developing successful new products.

The literature on new product development going back to Mansfield and Wagner (1975) has consistently identified the radically new product as the riskiest type to develop, but at the same time, the type of product, that, if it succeeds, yields the largest gain. This result is intuitively clear--a slight improvement in an existing product is likely to be well received by the marketplace, but hardly likely to be a runaway winner; those "big hits" come from more visionary, dramatic innovations.

Thus, new technologies often provide opportunities for significant market successes, but such success is realized much less frequently than firms might like.

In this paper, we will look at marketing research methods, both traditional and nontraditional, as ways to improve our ability to transform new technologies into products and services that "win" in the marketplace. In other words, we look to marketing research to limit technological oversights.

We proceed as follows. The next section provides a brief conceptual overview of the new product development process and the types of oversights that can occur. We then discuss the role that marketing research has traditionally played in improving new product success rates. We then provide a taxonomy of product/technology types and the sort of market research information that is most appropriate for each of those types. That taxonomy highlights the role that traditional and non-traditional market research needs to play to prevent technological oversights. We then discuss the need for a broader portfolio of marketing research methods to fill the gaps we have identified earlier. We conclude with an assessment of the potential and the limitations of 
marketing research to address the prevalence of technological oversights. A closely related topicthat we do address in this paper--the fostering of creativity in new product developing: increasing foresights--uses many of the same research methods. For an extensive review of the idea generation literature see Urban and Hauser (1993).

\section{New Product Development and Technological Oversights}

The aim of Marketing is to know and understand the customer so well that the product or service fits him and sells itself

\section{Peter Drucker}

The factors that emerge as being the most important to success of a technological innovation are those related to the importance of need satisfaction.

Rothwell

...but always, regardless of the amount, $R \& D$ money has gone to the development of instruments for which there was a real need.

Hewlett-Packard

The three quotes above put a market or customer orientation on the new product development process. In these days of "customer satisfaction," "delighting the customer," "total quality management" and the like, the focus is squarely on the customer as the final arbiter of market success. This is as it should be (at least according to marketers in a free market economy). And the various models for successful new product development put the customer at the core of the process. For example, Cooper (1986) recommends a seven stage "game plan" for new product development:

1. Idea generation

2. Preliminary assessment

3. Concept definition

4. Product development
5. Testing

6. Trial

7. Launch 
Using this framework (other texts, like Urban and Hauser, 1993, provide similar structures), we consider below the role of customer input to avoid oversights. But first we must distinguish between two classes of oversights.

\section{O versight Class 1: Radically new product market "disappointments." There is an} extensive literature on new product successes and failures, but that literature is quite ambiguous on what "failure" means. For the discussion here, we use the rather vague term disappointment to refer to the two situations that are most commonly deemed "failures" in the literature: (a) the actual rate of penetration into the market is significantly lower than what the organization had expected or planned for OR (b) the ultimate level of penetration (sales, market share or a similar measure) is significantly below the level anticipated. Note, then, that this disappointment is situation and firmspecific: a penetration rate that satisfies firm A may not satisfy firms B. Note also that by the term "radical" we mean a product whose use or function is new or uncertain to the customer. By this definition, a new technology that is hidden from the customer (a RISC chip vs. a 486 chip that can run the same software) is not radical from the customer's perspective, while a technology like interactive television that is radically new to the customer would be radical.

\section{O versight Class 2: Technology missing new product opportunities. For this type of} oversight, a "potential" successful new product exists, but marketers ignore or overlook the opportunity. This is not a failure or "disappointment," except perhaps in retrospect; it is an opportunity cost loss in some sense however.

Exhibit 1 summarizes these two classes of oversights and their relationship to the new product performance of the firm. As that Exhibit indicates, introducing high potential products effectively and eliminating market failures is where marketing research can 


\section{Exhibit 1}

Relationship Between Market Potential and Firm's Marketing Actions

\begin{tabular}{|c|c|c|}
\hline \multirow{2}{*}{$\begin{array}{l}\text { Expected market } \\
\text { potential for the } \\
\text { new product }\end{array}$} & \multicolumn{2}{|c|}{$\begin{array}{l}\text { Firm's marketing actions } \\
\text { with respect to the new product }\end{array}$} \\
\hline & $\begin{array}{l}\text { Pursue the project } \\
\text { (introduce, etc.) }\end{array}$ & Ignore the idea \\
\hline High & $\begin{array}{c}1 \\
\text { Success, or good foresight }\end{array}$ & $\begin{array}{c}2 \\
\text { Oversight class } 2: \\
\text { Lack of foresight or sin of } \\
\text { omission }\end{array}$ \\
\hline Low & $\begin{array}{c}3 \\
\text { Oversight class 1: } \\
\text { Market disappointment or } \\
\text { sin of commission }\end{array}$ & $\begin{array}{c}4 \\
\text { No disappointment: } \\
\text { Good foresight }\end{array}$ \\
\hline
\end{tabular}


contribute. Correct decisions that emerge from cells 1 and 4 in that exhibit represent good foresight, often resulting from effective marketing research. The other two cells reflect the two oversight cases we will focus on: cell 2 misses an opportunity and is a sin of omission, while cell 3 reflects introduction of a losing product and is a sin of commission.

Note that Class 1 and Class 2 errors here correspond to the false positives and false negatives in Garud, Nayyar and Shapira (1994). The role of the marketing research methods that we develop here is to shrink both types of error probabilities--i.e., to increase the correlation between actual and predicted market performance.

How then do our two classes of oversights intersect with the seven stage game plan above? Oversight class 1 produces products whose market assessments are too optimistic in one way or another. Stages 2, 5 and 6 represent increasingly detailed attempts at market assessment. Oversights in this class must have been associated with overly optimistic market research assessments in one of those three stages.

Oversight class 2 is relatively easy: as no product is developed, there is either a flaw in the idea generation process or the product is screened out as unworthy of launch during one of stages 2 to 6 . Note that an error in stage 1 is an oversight of ignorance; an error in stages 2 to 6 is a market misassessment on the low side.

In order to address these two classes of oversights, we must understand why they occur. There is an extensive literature on new product successes and failures (Booz, Allen and Hamilton, 1971, 1982; Duerr, 1986; Cooper and Kleinschmidt, 1987; de Brentani, 1989; Yoon and Lilien, 1985, Lilien and Yoon, 1989; Rothwell et al., 1974; Cooper, 
1975 for example) that provide some consistent clues. For example, for oversight class 1, when market assessments are too optimistic, nine of the reasons that emerge are:

OI I Lack of customer learning. By our definition, radically new products often require customers to change some of their consumption behavior. Even if the end seems clearly desirable, inertia often plays a key role in thwarting radically new product acceptance. Note that after a century, the QWERTY keyboard, originally developed to retard the typing speed of moveable type-setters (to avoid type-jams), is still the standard in spite of many attempts to introduce more sensible alternatives.

01.2 Lack of complete solution The penetration of the PC was considerably accelerated by the development of associated word-processing and spreadsheet software. Note that these developments came from different organizations, so that each innovation was an incomplete solution to a customer need.

01.3 Early bugs. Many organizations underestimate the power of negative word-ofmouth. A classical example involves the early field problems with heat pumps introduced in the early '50s. Those problems poisoned the market for heat pumps until the next generation of heating and cooling contractors emerged almost two decades later.

01.4 Value M isassessment. When solar heating systems were first introduced, early customer surveys showed high interest and high intention to buy. Most market forecasts from those data were much too high: as customers learned more about the real, total system costs (including initial costs, system lifetime, system maintenance, likelihood of hoe damage due to system failure etc.), their likelihood of purchase 
decreased. Realistic economic calculations early on would have provided more pessimistic forecasts (Lilien and Johnston, 1980).

01.5 Technology Choice Confusion. Customers often do not choose the "best" alternative in isolation if that alternative must fit into a system. Many people believed that the Beta format was superior technically to the VHS tape format. However, the penetration of associated software in video rental stores for VHS, made VHS players more attractive. Beta lost. Similar arguments hold for the penetration of Macintosh vs. the PC.

01.6 Initial cost too high. When energy efficient refrigerators, air conditioners and the like emerged, manufacturers assumed that consumers would buy them because their life cycle savings would more than compensate for the higher initial cost. Hausman (1979) has shown that consumers use much higher implicit discount rates than manufacturers normally expect; market penetration for energy efficient appliances was much slower than anticipated.

01.7 Short lifecycles and leapfrogging. If customers have been taught to expect a new technology to arrive on a regular basis they may delay purchase indefinitely. Many consumers who considered buying fax machines were put off by the frequent changes in options and configurations. Some have now bypassed the fax option completely, using alternatives that are completely electronic.

01.8 Channel resistance. In many markets, new product plans require cooperation from the salesforce and/or distributors. If existing products are easier to sell and if the salesforce is compensated on a fixed percent of sales basis, the salesforce or other 
intermediaries will allocate less time to selling the new product than is in the best long term interest of the firm (Dearden and Lilien, 1990).

01.9 W rong target market. A radically new product often provides little real benefit to the original target market, but may have benefit in other markets. Video conferencing was originally thought to provide large potential advantages to multi-location organizations. It turns out that many types of interaction and communication take place face-to-face that cannot be accommodated in a video-conference--that market did not embrace the innovation. The same technology has been quite successful amongst networks of medical schools, where rare cases or new medical procedures can be shared with students and colleagues at remote locations.

Now let us consider type 2 oversights, those where a market opportunity actually exists that is being ignored by potential firms. Note, that the evidence in this area contains sample selection bias: we only learn about such oversights if, after the fact, someone does take advantage of the technological opportunity. The patent office may be full of latent opportunities, and new product texts recommend that firms make regular use of patent searches. For example: ". ..a highly successful entrepreneur in a Canadian firm conceded that most of his successful new product ideas were the result of a regular review of patents..." (Cooper, 1986, p77). Thus the evidence about the second type of oversights emerges only ex post, if at all. Some of the most common reasons for such oversights are:

02.1 Lack of efficient or effective search. Most of the failures of this type are due to lack of vision or imagination. Somehow, the early developers simply did not "know what they had." Why didn't Xerox's Palo Alto Labs see the potential in the operating 
system that eventually became the heart of the Macintosh? What did Apple see that Xerox didn't?

02.2 No customer understanding. A technology may be developed by an R\&D lab in a market that differs from the market in which a need exists. Indeed, Lee and Na (1994) show that radically new products are most likely to emerge from outside the industry-those with the technology often do not understand the full range of possible market needs they might serve.

02.3 Lack of imagination. Many technological innovations represent the "potential" to produce new products. The accidental development of a "not-so-sticky" adhesive at 3M lead to the market for the Post-It notes. How many other organizations have similar "opportunities" that they are simply ignoring?

02.4 Lack of resourceslcompetencies. If a firm develops a radically new product but lacks access to channels (access to shelf space in supermarkets, for example) a major potential success may be missed.

02.5 Missing value in synergies. This is related but slightly different from the above. When videotex was introduced in areas of Florida by U.S. Knight Ridder in 1983, there was not enough software on the system to justify the customer investment in the hardware. With the range of information available today on private computer networks and on the Internet, customer investment in technology is now justifiable.

02.6 Technology changes customer behavior. Radical innovations may not simply substitute for existing products, they may make wholesale changes in the ways consumers operate. When xerography was introduced, IBM turned down the 
technology, assuming it would merely substitute for carbon paper. And the original estimate for the market potential for digital computers worldwide was far fewer than ten. These are two technologies that have changed the way business is done.

What are the implications of the above from the standpoint of marketing research? First, we take as given that the customer is the final arbiter of product-value. Thus, an exchange will take place if a customer finds the new product "worth the money." Hence, understanding how customers are likely to act--the focus of much of marketing research--is central to redressing the oversights we have identified above. Within the framework of radically new (to the customer) products, we must consider how the portfolio of existing marketing research tools can be used and what needs exist for other forms of marketing research.

In the next section we review the current portfolio of marketing research procedures aimed at developing and assessing the market for radically new products. Most new products are NOT radically new; rather, they allow customers to do things a bit better, faster or cheaper or add some variety to an existing product mix. Customers can generally give reliable assessments of their likely behavior if the situation (new product) presented to them is within their realm of previous experience, i.e., what we refer to as marginally new. Most of us (except for a few visionaries) have difficulty imagining well outside that realm, suggesting that we may need other sources of market information to overcome the oversights outlined here.

More precisely, and always taking the customer's perspective, we call a new product marginally new if a close substitute to it exists in the marketplace. A new color copier that is a bit faster in its output, can easily be evaluated by a customer because it is similar to products that the customer is familiar with; a color copier with both fax and 
personal computer printing capabilities would be more difficult to evaluate because it does not fall into any established current category and combines several technologies not currently available together. These two types of new products are also called evolutionary innovations and revolutionary innovations, respectively.

\section{Research Methods for New Product Development}

There is a vast literature (see Urban and Hauser( 1993) or Cooper (1986) for a review) that indicates that new products have higher success rates and better returns on new product investment when their development and evolution follow a systematic procedure of research and testing. New product research methods track the new product development process stages we highlighted above and generally address the issues that arise in idea generation, preliminary assessment, concept definition and testing. In general, the most widely used methods are geared toward marginally new products.

Exhibit 2 provides a taxonomy of methods, classified by type of product and research method type. The traditional methods used for marginally products (box 3) are:

Concept testing methods, used to get an early idea of how the target market responds to the "idea" of the new product. Early concept tests use informal focus groups for qualitative evaluations; later in the screening procedure, more formal preference and intent-to purchase measures are used amongst a sample of target customers (Urban and Hauser, 1993).

Product design methods, used to determine those features that should be included most cost effectively in the new product. Conjoint analysis is the most frequently used method for this purpose (Wittink and Cattin, 1989). 


\section{Exhibit 2}

\section{A Taxonomy of Marketing Research Methods for New Product Development}

\begin{tabular}{|c|c|c|}
\hline \multirow[t]{2}{*}{ Type of New Product } & \multicolumn{2}{|c|}{ Nature of Research Method } \\
\hline & Traditional & Non-traditional \\
\hline Radically New & $\begin{array}{l}\text { (1) } \\
\text { - Market definition and } \\
\text { market structure analysis } \\
\text { methods } \\
\text { - Forecasting methods } \\
\text { using analogy } \\
\text { - Value assessment } \\
\text { technique } \\
\text { - Morphological analysis }\end{array}$ & $\begin{array}{l}\text { - }(2) \\
\text { - Lrainstorming methods } \\
\text { technique } \\
\text { - Information acceleration } \\
\text { methods } \\
\text { - Virtual reality based } \\
\text { research methods }\end{array}$ \\
\hline Marginally New & $\begin{array}{l}\text { (3) } \\
\text { - Concept testing methods } \\
\text { - Product design methods } \\
\text { - Product testing methods } \\
\text { analysis } \\
\text { - Pretest market } \\
\text { assessment methods } \\
\text { - Test marketing methods }\end{array}$ & (4) \\
\hline
\end{tabular}


Product testing methods, used to see how customers react to the actual product, usually in the laboratory. For the most part small groups of customers or prospects are used for product testing (Urban and Hauser, 1993).

Benefit segmentation analysis, used to determine segments of customers that have similar needs so that their preferences can be matched with appropriate new products. (Haley, 1968; Kamakura, 1988)

Pre-test market assessment methods, usually used as an intermediary step between product testing and test marketing. Here, several hundred customers are usually recruited or intercepted and put through a simulated shopping situation to provide an early indication of likely test market results (Silk and Urban, 1978).

Test marketing methods, used for evaluating the market response to a new product by introducing it locally, in one or more market areas, and carefully tracking the results (Blattberg and Golanty, 1978).

These methods all assume customers are familiar with the product category and do not have to make any major modifications to their choice processes when considering the new product.

To see more clearly where problems with existing methods arise, let us focus on concept testing methods and the research decisions that are associated with them. We deal with two issues that arise in attempting to apply concept testing methods to radically new product. Specifically we focus on (A) describing new product concepts to subjects effectively (with related data collection issues) and (B) choosing an appropriate sample. 
In describing new product concepts (issue A) we see three main subissues: (1) whether or not any comparative information is to be provided (or, indeed, is relevant), (2) what type of information (factual or emotional) we should try to obtain, and (3) what the effect of the subject's knowledge is on the quality of the response.

Issue A.1: Stand alone or competitive test. There are two popular types of test-designs: i) Monadic; and ii) Competitive. In a monadic design, a subject is given only one concept to be evaluated. In a competitive design, the new concept being tested is presented along with those of some present brands. Summarizing previous use of these two techniques, Moore (1982) notes that both methods have had considerable successes in predicting trial. Admitting a lack of any serious research to compare these two methods, he hypothesizes that monadic tests are preferable when it is hard to identify direct competitors or when there is little search prior to purchase. In radically new products context it appears that monadic tests might be more appropriate.

Issue A.2: Rational answers or 'emotional' answers from subjects. Axelrod and Wybenga (1985) argue that it is not enough just to know the rating (or ranking) of a product concept; it is equally important to know why the subject likes (or dislikes) that concept. Evaluative questions, such as what rating will give you this product concept? are good for getting only a rational response from the subject. To obtain subjects' emotional reasons for preferring a product concept alternative, more perceptual questions, such as how does this product concept differ from the others, should be asked. Radically new products may require subjects to change their method of evaluation dramatically and, thus, normally require perceptual questions. 
Issue A.3: Concept Evaluation Result- Sensitivity to Subject Knowledge. In concept testing it is generally assumed that subjects understand the product concept they are evaluating. The evaluation of a concept can be severely affected by level of the respondent's knowledge of the product concept. In the absence of full knowledge, the subject will augment the information with his prior experiences and subjective judgments. Thus, the researcher can not be sure whether the subject is giving his true preferences or providing biased responses based on his augmentation of the information provided (Reidenbach and Grimes, 1984). For radically new products, the level of information that the subjects have about the product and the competitive environment must be carefully controlled for results to be valid. Note that subjects vary in degree of product knowledge. Knowledgeable subjects tend to give more valid responses; less knowledgeable subjects rely on reference groups (what he/or she believes to be the right answer within his or her group of peers) and core values (generic rather than specific product choice variables). Finally, different subjects have different information processing capabilities and may need different amounts of time to understand a new product idea (Berning, Kohn and Jacob, 1974). Based on such a premise, Tauber (1981) suggests that, like for advertising copy testing, new product concepts should be comprehension-tested before administration.

Issue B: Choosing a sample. While the literature on concept testing suggests that the sample should be drawn probabilistically to be able to project to the market, it is not clear that such a random sample can give sound evaluations for radically new products. The points raised above about the effect of knowledge level on concept evaluation are also valid for the purpose of choosing a sample. If the concept test is for a complex product such as a CD-ROM, then knowledgeable people would be able to give more valid evaluations of the features of the new product than less knowledgeable individuals. 
Thus, we see that with a radically new product, the rules of the research game are quite different than the rules for marginal products (see Exhibit 3). First, the competitive set to be used for evaluating the radically new product either does not exist or is not easy to define for conducting evaluative research. Further, the researcher may find it hard to create and accurately describe an environment to the respondent about the use situation. Also, it is not clear whether the researcher can identify an appropriate group of respondents who can assimilate the information presented and provide accurate evaluations required for assessing the new product. 


\section{Exhibit 3}

Some Factors Inhibiting The Direct Application Of Traditional New Product Development Methods For Radically New Products

Phase of NPD

Process Solutions

Idea generation

Preliminary assessment

Concept definition and testing
Factors

Thinking limited by available technologies

Limited by a lack of understanding of the customer's choice process

Customer limited by lack of appreciation of the potential of the new product.

Limited by ability to define the new concept

\section{Potential Solutions}

Need to consult

visionaries and experts

Study of choice process under conditions of expected availability of the new product among expert users.
Need to utilize better methods to communicate the new product concept 


\section{Research Tools for Radically New Products}

Some "traditional" marketing research tools have been able to provide some limited success for the market assessment for radically new products (Exhibit 2, Box 1). They are:

\section{Market definition and market structure analysis methods, which attempt to map} customer attitudes or behaviors against the position of competitive brands. Such methods usually focus on either the clustering of customer-attitudes (as in benefit segmentation, above) or determining the substitution between products (Urban and Hauser, 1993).

Forecasting methods using analogies, where a product is matched (either physically or through its customer-benefit characteristics) with another similar product in order to assess both the rate of market penetration and the ultimate market potential for the product (Fisher and Pry, 197 1; Choffray and Lilien, 1986).

Value assessment techniques, usually applied in non-consumer markets. Here, interviews are conducted at customer firms to determine a comprehensive listing of cost elements associated with the usage of radically new product offering compared with the current operation (i.e., life cycle costing). Values are then associated with the cost elements to estimate the overall value to the customer of the new product (at a specific price) in that application. Alternatively, a full simulation model of the customer's operation can be developed (Anderson, Jain and Chintagunta, 1993).

Morphological analysis, a method for new product idea generation, where a product is decomposed into its attributes and all possible combinations of those attributes are evaluated as possible "new products" (Adams, 1972). 
While these methods have been used with some success for radically new products, a number of non-traditional tools have emerged recently due, primarily, to two reasons: (i) limitations in the ability of the researcher to realistically present information on the characteristics and use of the new product to the potential user, and (ii) limitations in the ability to identify the "appropriate" group of potential customers for eliciting reaction to the new product idea. To address the first issue requires an accurate conceptualization of new product's features as well as a clear, comprehensible way of presenting them to respondents. In this respect, technological developments in the area of virtual reality have been employed in a few cases. A technique called information acceleration based on virtual reality is discussed below.

The second issue --identifying the appropriate respondent group--is a continuing challenge. One must identify visionaries, experts, or innovators for eliciting responses. Also, statistical forecasting methods using representative samples may need to be replaced by "biased"-- leading edge individuals--in order to review the new product under the most favorable circumstances. Thus, researchers must be creative, identifying visionaries or perhaps acting as visionaries themselves.

We suggest four non-traditional methods that may have some value for radically new products: brainstorming methods, the lead user technique, information acceleration and methods based on virtual reality.

Brainstorming Methods: These methods involve discussion among a group of appropriate respondents on the radically new product. Such discussions are typically conducted under the direction of an experienced moderator. The basic idea has been implemented in a variety of ways (Arnold, 1962, Prince, 1972). 
Lead U ser Technique: This technique involves studying the viability of a new product using a sample of current users of a firm's products whose present specific needs will become general in the marketplace months or years in the future. By studying such a group, the firm may identify the characteristics of the innovation to be developed as well as the potential of a new product under consideration. This technique may be more advantageous than a traditional focus group method because members of a focus group are generally constrained by current experience with existing products. Lead users, on the other hand, are those who have developed solutions to problems encountered with existing products (see von Hippel 1986, 1988, and Urban and von Hippel 1988).

Information Acceleration: This method recognizes that a customer will be considering a new product in a "future world," while the testing is being conducted in a current world. The technique is designed to place the individual in the information-base of the future world. Thus, information acceleration attempts to create a simulated environment for assessing the effects of future information that can be made available via various media to consumers. Hauser, Urban, and Weinberg (1993) implemented this method to assess the demand for a new automobile using the format of a multimedia personal computer. Various visual and verbal information on the new product was stored on a video disk. The consumer (respondent) accessed this information from the computer's keyboard, mouse, or other input device by pointing to and choosing an icon or picture representing the information source. In one study, consumers had four types of information on the vehicle: advertisements, unrehearsed interviews with actual consumers to simulate word-of-mouth effects, articles on the product published in such magazines as Consumer Reports and trade publications such as $\mathbf{C}$ ar and Driver, and a showroom encounter. In the showroom encounter, the respondent could have 
interactions with a salesperson, walk around the automobile, look at the manufacturer's price sticker or look at a brochure on the automobile. The authors collected data on purchase intentions after exposure to any information source as well as at the end of the session on information gathering in the multimedia laboratory.

Virtual Reality-Based Research The information acceleration method described above is but one technique based on the emerging field of virtual reality-based research. This technology goes by several names including multimedia, hypermedia, intermedia, and compact disc-interactive. It is difficult to predict where this technology will go but it has many practical uses. In particular, it offers innovative ways of presenting new product concepts to potential users for eliciting their reactions. These methods are reported to have been employed in such projects as the development of theme parks (Economist 1993), development of "new" credit unions (Pels and Merrick 1993), and the design of magazines (Crispell 1993). Various advantages and potential of virtual reality are described by Goerne (1992).

\section{Conclusions}

In this article we have suggested a number of reasons why radically new products fail to achieve full market success and how marketing research methods can (or might) be used to increase the rate of success. We suggest that a firm's failure to exploit a new technology can be largely attributed to its inability to match appropriate marketing

research methods with the specific new product assessment problem. We have identified two major problem-sources: a developer's inability to communicate or define the new product concept in a meaningful way and inappropriate selection of potential evaluators of the concept. Solutions to these problems--such as testing among experts or visionaries, indirect customer value assessment procedures, the use of information 
acceleration concepts and the use of virtual reality technology for describing the new product--have the potential to address many of these problems.

We have proceeded in this paper under the assumption that neither the technology (radically vs. marginally), nor the type of customer (consumer vs. industrial), nor the type of innovation (product vs. service, for example) affects the appropriateness of the market research method one might employ. As there are horses for courses, there are market research methods more appropriate for some of the situations above than for others. While we do not have any global guidelines in mind, we suggest the following:

1. The technology is not critical in determining a research method; it is the consumer's response to the technology that matters.

2. Services need to be experienced; here traditional product testing methods (trialing) should be considered as well as virtual reality based research.

3. Process innovations, particularly in non-consumer markets, can provide economic value (cost reductions) without changing functionality. Hence, value assessment methods are most appropriate here.

4. Also, in those business markets where organizational needs emerge at different times for different customers, the lead user method would appear apt.

5. Finally, consumers reduce adoption risk by acquiring information. The information acceleration method appears most apt for use in the consumer durables marketplace where adoption risk is higher than for consumables. 
We believe that new ideas and techniques are needed to adapt the existing array of new product development methods to radically new products. For example, marketing researchers need a theory of customer behavior under conditions of new product unavailability: this situation arises when a firm announces that a radically new product will be launched at a future time. Similarly, our methods assume a static set of preferences or needs amongst customers; radically new products are likely to change "needs" as customers build an understanding of "what might be." Dynamic customer preference models and new, associated research methods are likely to be needed here.

There is also a clear need to scan the scientific laboratory or R\&D environment to determine what "best practices" are in selecting radically new product development projects to pursue. Such a study could assess the extent to which firms are missing opportunities for new technological products as well as determine what firms have been doing that has worked for them--i.e., what have they done that has made them successful in realizing the potential of a radically new product. Such a best practices study could result in formal codification of those practices and become a rule-based or expert system method for radically new product market assessment.

In sum, existing marketing research methods have much to offer in addressing technological oversights, especially when those methods are carefully tuned to the problems that radically new products evoke. However, there are some exciting challenges and opportunities to move the field forward significantly and we expect important advances in this area in the years to come. 


\section{REFERENCES}

Adams, L. (1972) Conceptual Blockbusting. The Portable Stanford. Stanford, CA.

Anderson, Jain and Chintagunta (1993) "Customer Value Assessment in Business Markets: A State of Practice Study," Journal of Business to Business Marketing, Vol. 1, pp. 3-29.

Arnold, J. E. (1962) "Useful Creative Techniques" in Source Book of Creative Thinking, eds. S. J. Pames and H. F. Harding, New York: Charles Scribner's Sons.

Axelrod, Joel N. and Wybenga Hans (1985), "Perceptions That Motivate Purchase," Journal of Advertising Research, Vol. 25, No. 2, pp. 19-21.

Blattberg, R. and J. Golanty (1978) "TRACKER: An Early Test Market Forecasting and Diagnostic Model for New Product Planning," Journal of Marketing, 44 (Fall) pp. 59-67.

Booz, Allen and Hamilton (1971) Management of New Products (New York: Booz, Allen and Hamilton).

Booz, Allen and Hamilton (1982) New Product Management for the '80s (New York: Booz, Allen and Hamilton).

Brockoff, Klaus and Vithala R. Rao (1993) "Toward a Demand Forecasting Model for Preannounced New Technological Products," Journal of Engineering Technology M anagement, Vol. 10 (December), pp. 21 1-228.

Choffray, Jean-Marie and Gary L. Lilien (1986) "A Decision Support System for Evaluating Sales Prospects and Launch Strategies for New Products" Industrial Marketing Management, 15 (February) pp. 75-85.

Cooper, R. G (1975) "Why New Industrial Products Fail" Industrial Marketing Management Vol. 4, No. 2 (December) pp. 315-326.

Cooper, R. G. and E. J. Kleinschmidt (1987) "New Products: What Separates Winners from Losers?" Journal of Product Innovation Management, Vol. 4, pp. 169- 184.

Cooper, Robert G. (1986) Winning at New Products. Reading MA: Addison Wesley.

Crispell, Diane (1993) "Virtual Reality Meets Do-It-Yourself," Folio: The Magazine for Magazine Management, Vol. 22, No. 9 (May 15), pp. 25-26.

De Brentani, U. (1989) "Success and Failure in New Industrial Services," Journal of Product Innovation Management, Vol. 6, No. 4, pp. 239-258. 
Dearden, James A. and Gary L. Lilien (1990) "On Optimal Salesforce Compensation in the Presence of Learning Effects" International Journal of Research in Marketing, Vol. 7, No. 2 (December), pp. 179-188.

Duerr, M. G (1986) The Commercial Development of New Products, New York: The Conference Board.

Economist, "Theme Parks: Heart, Brains, and Jobs," September 4, 1993, Vol. 328, No. 7827, p. 33.

Fisher, J. C. and R. H. Pry (1971) “A Simple Substitution Model for Technological Change," Technological Forecasting and Social Change, Vol. 2 (May), pp. 75-88.

Goerne, Carrie, "Visionary Marketer Shape for Concrete Gains from the Fantasy of Virtual Reality," Marketing News, December 7, 1992, Vol. 26, No. 25, p. 2.

Garud, Raghu; Nayyar, Praveen R. and Shapira, Zur (1994) "Technological Choices and the Inevitability of Errors," NYU Conference on Technological Oversights and Foresights, 11-12 March.

Haley, R. I. (1968) "Benefit Segmentation: A Decision Oriented Research Tool," Journal of Marketing, Vol. 32 (July), pp. 30-35.

Haley, Russell and Gatty, Ronald (197 1) "The Trouble with Concept Testing”, Journal of Marketing Research, Vol. 8, p. 23.

Hauser, John R., Glen L. Urban, and Bruce D. Weinberg, "How Consumers Allocate Their Time When Searching for Information," Journal of Marketing Research, Vol. 30 (November 1993), 452-466.

Hausman, Jerry A. (1979) "Individual Discount Rates and the Purchase and Utilization of Energy-Using Durables," Bell Journal of Economics, 10 (1) pp. 33-54.

Kamakura, W. A. (1988) "A Least Squares Procedure for Benefit Segmentation with Conjoint Experiments," Journal of Marketing R esearch, Vol. 25 (May) pp. 157-167.

Lee, M. and D. Na (1994) "Determinants of Technical Success in Product Innovation When Innovative Radicalness is Considered," Journal of Product Innovation Management Vol. 11, No. 1 (January) pp. 62-67.

Lilien, Gary L. and Eunsang Yoon (1989), "Determination of New Industrial Product Performance: A Strategic Reexamination of the Empirical Literature," ZEEE Transactions on Engineering Management, 36 (February) pp. 3-10.

Lilien, Gary L. and Paul E. Johnston (1980) A Market Assessment for Active Heating and Cooling Products. DOE Contract AC03-79CS-30209. September. 
Mansfield, E. and S. Wagner (1975) "Organizational and Strategic Factoes Associated with Probabilities of Success in Industrial R\&D," The Journal of Business 48 (April) pp. 179-198.

Moore, William L. (1982), "Concept Testing", Journal of Business Research, Vol. 10, pp. 279-294.

Pels, Mary-Ann and Bill Merrick (1993) "2001: A Credit Union Odyssey," CreditU nion Magazine, Vol. 59, No. 7, (July), pp. 40-45.

Prince, G. M. (1972) The Practice of Creativity, N ew York: Collier Books.

Reidenbach, Eric R. and Grimes Sharon (1984), "How Concept Knowledge Affects Concept Evaluation", Journal of Product Innovation Management, 4, 255-266.

Rothwell, R. et al. (1974) "Sappho Updated: Project Sappho Phase II" R esearch Policy , Vol. 3, pp. 258-291.

Silk, Alvin J. and Glen L. Urban (1978) "Pre-test Market Evaluation of New Packaged Goods:A Model and Measurement Methodology" Journal of M arketing Research, Vol. 15, No. 2, pp. 171-191.

Tauber, Edward M. (1972), "What is Measured by Concept Testing", Journal of Consumer Research, Vol. 12 (Dec.), pp. 35-37.

Tauber, Edward M. (1981) "Utilization of Concept Testing for New Product Forecasting: Traditional Versus Multiattribute Approaches", in Yoram Wind, Vijay Mahajan, and Richard N. Cardozo (Eds.), New Product Forecasting Lexington, MA: Lexington, pp. 169-178.

Urban, G. L. and J. R. Hauser (1993) Design and Marketing of New Products, 2nd Edition, Englewood Cliffs, N.J.: Prentice Hall.

Urban, Glen L. and Eric von Hippel(1988) "Lead User Analysis for the Development of New Industrial Products," Management Science, Vol. 34, pp. 569-582.

von Hippel, Eric (1986) "Lead Users: A Source of Novel Product Concepts," Management Science, Vol. 32, pp. 791-805.

Wittink, Dick R. and Phillip Cattin (1989) "Commercial Use of Conjoint Analysis: An Update," Journal of Marketing, Vol. 53 (July), pp. 91-96.

Yoon, Eunsang and Gary L. Lilien (1985) "New Industrial Product Performance: The Impact of Market Characteristics and Strategy," Journal of Product Innovation Management, Vol. 3 (September), pp. 134-144. 